\title{
The proapoptotic BH3-only protein BAD transduces cell death signals independently of its interaction with Bcl-2
}

\author{
M Adachi ${ }^{\star, 1,2}$ and $\mathrm{K}$ Imai ${ }^{2}$ \\ ${ }^{1}$ Division of Molecular Oncology and Molecular Diagnosis, Graduate School of \\ Medicine, Sapporo Medical University, Sapporo, Japan \\ ${ }^{2}$ First Department of Internal Medicine, Sapporo Medical University, Sapporo, \\ Japan \\ * Corresponding author: M Adachi, The First Department of Internal Medicine, \\ Graduate School of Medicine, Sapporo Medical University, Sapporo, Japan. \\ Fax: 81-11-611-2282; E-mail: adachi@sapmed.ac.jp
}

Received 30.4.02; revised 2.7.02; accepted 10.7.02

Edited by $\mathrm{H}$ Ichijo

\section{Abstract}

The BH3-only protein BAD binds to Bcl-2 family proteins through its $B H 3$ domain. Recent studies suggest that $B A D$ binds to both $\mathrm{Bcl}-2$ and $\mathrm{Bcl}-\mathrm{X}_{\mathrm{L}}$, however mediates its proapoptotic functions through inhibition of $B c l-X_{L}$, but not Bcl-2. In this paper we addressed this issue using a BAD mutant within the BH3 domain, by substitution of Asp 119 with Gly $\left(B A D_{D 119 G}\right)$, which selectively abrogates an ability to interact with Bcl-2. Confocal microscopy revealed that mutation of $B A D$ at $D 119$ does not affect BAD targeting to the mitochondrial membrane in serum-starved COS-7 cells. However, co-precipitation assays indicated that, whereas wild-type $B A D$ (BADwt) directly interacts with $\mathrm{Bcl}-2$ and $\mathrm{Bcl}$ $X_{L}, B A D_{D 119 G}$ interacts only with $B c l-X_{L}$. Nevertheless both $B A D w t$ and $B A D_{D 119 G}$ could introduce apoptosis and diminish the anti-apoptotic effect of $B c l-2$ and $B c l-X_{L}$ in a similar manner in a co-transfection assay. These data thus suggest that Asp119 is a crucial site within the $\mathrm{BH} 3$ domain of $B A D$ for interaction of $B A D$ with $B c l-2$, but is dispensable for the interaction of $B A D$ with $B c l-X_{L}$, for its targeting to mitochondria, and most importantly, for its pro-apoptotic functions. Thus, we confirm that neutralization of $\mathrm{Bcl}-2$ function is marginal for BAD-mediated apoptosis.

Cell Death and Differentiation (2002) 9, 1240-1247. doi:10.1038/sj.cdd.4401097

Keywords: BAD; apoptosis; Bcl-2 family; $\mathrm{BH} 3$ domain; phosphorylation

Abbreviations: GFP, green fluorescent protein; GST, glutathione S-transferase

\section{Introduction}

Bcl-2 family proteins can function to either positively or negatively regulate apoptosis. Anti-apoptotic members of this family include Bcl-2, Bcl-X $\mathrm{X}_{\mathrm{L}}$, Bcl-w, BHRF1, and E1B-19K, while pro-apoptotic family members include Bax, Bak, and
Bok. These molecules share homologous domains $\mathrm{BH} 1$ to $\mathrm{BH} 4$ (reviewed $\mathrm{in}^{1,2}$ ). Bcl-2 proteins interact with other molecules which express an $\alpha$-helical structure termed the $\mathrm{BH} 3$-domain and this interaction is believed to be important in the regulation of apoptosis (reviewed $\mathrm{in}^{3}$ ). A large number of $\mathrm{BH} 3-$ only proteins have been identified including BAD, Bid, Bik, Bim, Bmf, ${ }^{4}$ BNIP3, Hrk, and Noxa. ${ }^{5}$ All of these BH3-only proteins are pro-apoptotic molecules and their pro-apoptotic activity is believed to be mediated via interaction with $\mathrm{Bcl}-2$ family proteins. Thus the $\mathrm{BH} 3$ domain of these proteins is believed to be crucial for their pro-apoptotic functions.

$\mathrm{BH} 3-$ only proteins can be divided into two groups. The first group of $\mathrm{BH} 3$-only proteins, which includes BAD and Bim, can bind anti-apoptotic molecules selectively, and inactivate their anti-apoptotic functions. For example, BAD is phosphorylated by survival signals, bound to 14-3-3 scaffold proteins and localized in the cytoplasm in an inactive form. ${ }^{6-8}$ Once survival signals are abrogated BAD is dephosphorylated, dissociated from 14-3-3 and localized to the mitochondria. Free, mitochondrial BAD molecules are then believed to interact with either $\mathrm{Bcl}-2$ or $\mathrm{Bcl}-\mathrm{X}_{\mathrm{L}}$ and neutralize their anti-apoptotic functions. Similarly, Bim is normally complexed with the microtubule-associated dynein light chain LC8. However once death signals are activated $\mathrm{Bim}$ is released from the complex. Free Bim then binds to $\mathrm{Bcl}-2$ or $\mathrm{Bcl}-\mathrm{X}_{\mathrm{L}}$ and inactivates their anti-apoptotic functions. ${ }^{9}$ Thus inhibition of the anti-apoptotic functions of $\mathrm{Bcl}-$ 2 family members appears to be a pivotal role of this group of pro-apoptotic $\mathrm{BH} 3$-only molecules. The second group of $\mathrm{BH}$-only proteins, which is exemplified by Bid, can bind to both anti-apoptotic and pro-apoptotic $\mathrm{Bcl}-2$ family members. Bid is localised in the cytoplasm in non-apoptotic cells. However activated caspase-8 cleaves p22 Bid to generate a p15 active tBid fragment which is then targeted to the mitochondria where it binds to the pro-apoptotic Bcl-2 family members Bax or Bak as well as to the anti-apoptotic $\mathrm{Bcl}-2 .^{10-12}$ Formation of tBid-Bax or tBid-Bak oligomers induces apoptotic signals. Importantly, neutralization of anti-apoptotic Bcl-2 family members is believed to play only a marginal role in induction of apoptosis by these proteins.

Recently, it has been found that BAD and Bim, which belong to the first group of BH3-only proteins described above, require expression of Bax or Bak for their proapoptotic functions. ${ }^{13}$ However since neither BAD nor Bim can directly interact with Bax or Bak it is unlikely that they can directly activate Bax or Bak. Indirect activation of Bax or Bak via inactivation of $\mathrm{Bcl}-2$ or $\mathrm{Bcl}-\mathrm{X}_{\mathrm{L}}$ has been proposed..$^{13}$ As described above the pro-apoptotic functions of BAD appear to be directly mediated through interaction of $B A D$ with $B c l-2$ or $B c l-X_{L}$ via the $B H 3$ domain of $B A D$ and subsequent inactivation of the pro-apoptotic activity of $\mathrm{Bcl}-2$ or $\mathrm{Bcl}-\mathrm{X}_{\mathrm{L}}$. In fact, elimination of the entire $\mathrm{BH} 3$ domain from BAD abrogates its ability to interact with $\mathrm{Bcl}-2$ 
family members and simultaneously abrogates its proapoptotic activity. ${ }^{8}$ Although BAD can interact with both $\mathrm{Bcl}-$ 2 and $\mathrm{Bcl}-\mathrm{X}_{\mathrm{L}}, \mathrm{BAD}$ binds more strongly to $\mathrm{Bcl}-\mathrm{X}_{\mathrm{L}}$ than $\mathrm{Bcl}-2$ and $B A D$ can reverse the death repressor activity of $B c l-X_{L}$, but not that of $\mathrm{Bcl}-2 .{ }^{6}$ In addition, survival signals induce the phosphorylation of $B A D$, which results in its dissociation from $\mathrm{Bcl}-\mathrm{X}_{\mathrm{L}}$, but not from $\mathrm{Bcl}-2 .{ }^{14}$ The accumulated data therefore suggests that the pro-apoptotic function of BAD is primarily mediated via its neutralization of $\mathrm{Bcl}-\mathrm{X}_{\mathrm{L}}$, and that the neutralization of $\mathrm{Bcl}-2$ by $\mathrm{BAD}$ plays a marginal role in this function of BAD. However, these studies are all indirect observations and it is also conceivable that the death repressor activity of $\mathrm{Bcl}-2$ is much stronger than that of $\mathrm{Bcl}-$ $X_{L}$, and thus can overcome the death activity of BAD.

Since $B A D$ interacts with both $B c l-2$ and $B c l-X_{L}$ via the $\mathrm{BH} 3$ domain, but interacts more strongly with $\mathrm{Bcl}-\mathrm{X}_{\mathrm{L}}{ }^{6}{ }^{6}$ it was a possibility the BAD might interact with these two molecules via different regions of the $\mathrm{BH} 3$ domain. To date, at least three reports have indicated that replacement of the conserved leucine $(\mathrm{L})$ residue within the $\mathrm{BH} 3$ domain of $B A D$, Noxa or Bmf with alanine $(A)$ extensively reduced their ability to bind $\mathrm{BCl}-2$ or $\mathrm{Bcl}-\mathrm{X}_{\mathrm{L}}$ and abolished their proapoptotic activity. ${ }^{4,5,8}$ However, to our knowledge, there has been no study to investigate whether a second residue, aspartic acid (D) at position 119, which is also well conserved among $\mathrm{BH} 3-d o m a i n s$ of $\mathrm{Bcl}-2$ family proteins, could contribute to the binding and pro-apoptotic function of BH3-only proteins. We therefore generated a mutant form of BAD with an amino acid substitution of Gly for Asp119 within the $\mathrm{BH} 3$ domain $\left(\mathrm{BAD}_{\mathrm{D} 119 \mathrm{G}}\right)$ and tested the effect of this mutation on BAD protein-protein interactions and $B A D$ function. We found that this mutation abolished the ability of $\mathrm{BAD}$ to interact with $\mathrm{Bcl}-2$, but had no effect on its binding to $\mathrm{Bcl}-\mathrm{X}_{\mathrm{L}}$. Thus different regions within the $\mathrm{BH} 3$ domain of $\mathrm{BAD}$ appear to differentially contribute to the interaction of $B A D$ with $\mathrm{Bcl}-2$ and $\mathrm{Bcl}-\mathrm{X}_{\mathrm{L}}$. Importantly, $\mathrm{BAD}_{\mathrm{D} 119 \mathrm{G}}$ was still targeted to the mitochondria and could induce apoptosis in COS-7 cells as effectively as BADwt. In addition, they can reverse the death repressor activity of $\mathrm{Bcl}-2$ and $\mathrm{Bcl}-\mathrm{X}_{\mathrm{L}}$ in a similar level. This study is the first conclusive demonstration that BAD can induce apoptotic signals independently of its interaction with the anti-apoptotic Bcl-2.

\section{Results}

\section{BAD overexpression augments apoptosis in COS-7 cells}

The BH3-only protein BAD is abundantly expressed in many epithelial cells and functions to induce apoptotic signals. ${ }^{6-8,15}$ This suggests that BAD may play pivotal roles in the maintenance of epithelial structure by execution of excess or abnormal cells. To analyze the function of BAD in epithelial cell death, and the role of the $\mathrm{BH} 3$ domain of $B A D$ in this function, we expressed GFP-tagged human full-length BAD (BADwt) or its $\mathrm{BH} 3$ domain deletion mutants in kidney epithelial COS-7 cells. When transfectants were deprived of FCS after transfection, overexpression of BADwt strongly induced cell death, but a BAD mutant, in which the entire $\mathrm{BH} 3$ domain has been deleted, could not induce cell death signals (Figure 1A).
This indicates that BAD overexpression is able to augment apoptosis in COS-7 cells, and confirms previous observations indicating that the $\mathrm{BH} 3$ domain of $\mathrm{BAD}$ is essential for induction of apoptosis and that deletion of the $\mathrm{BH} 3$ domain totally abrogates pro-apoptotic functions of BAD. ${ }^{7}$

\section{BADD119G mutant has proapoptotic activity}

The $\mathrm{BH} 3$ domains are well conserved among the BH3-only protein family and other Bcl-2 family members. Alignment of amino acid sequences of these $\mathrm{BH} 3$ domains clearly reveals two highly conserved residues, leucine (L) and aspartic acid (D) as shown in Figure 1B. Although the conserved leucine has been reported to be critical for pro-apoptotic activity of $B A D$ there have been no studies to date on the role of the conserved aspartic acid. We therefore determined the effect of a point mutation at this conserved aspartate on the proapoptotic activity of BAD. For this purpose we generated a mutant $\mathrm{BAD}\left(\mathrm{BAD}_{\mathrm{D} 119 \mathrm{G}}\right)$ in which the aspartate at aa 119 was mutated to glycine $(G)$ and investigated its pro-apoptotic activity in COS-7 cells. Transfection of a BAD D119G $_{\text {CDNA }}$ expression vector resulted in a lower level of BAD expression compared to transfection of wild-type BAD (BADwt) (Figure $1 C)$. However $B A D_{D 119 G}$ displayed a similar pro-apoptotic activity to that of BADwt, as assessed by cell death and activation of caspase-3 (Figure 1D, E). Thus the $B A D_{\mathrm{D} 119 \mathrm{G}}$ mutant may even have a higher pro-apoptotic activity than BADwt. Furthermore the well-conserved Asp among Bcl-2 family members appears to be dispensable for the proapoptotic activity of BAD.

\section{Mutation of BAD at aa119 in the $\mathrm{BH} 3$ domain abrogates its interaction with $\mathrm{Bcl}-2$}

The $\mathrm{BH} 3$ domain of $\mathrm{BAD}$ is believed to be crucial for the interaction of $\mathrm{BAD}$ with $\mathrm{Bcl}-2$ family members and subsequent inactivation of $\mathrm{Bcl}-2$ pro-apoptotic function. We therefore determined whether mutation of BAD at the conserved D119 position could alter the interaction of BAD with Bcl-2 family proteins. For this study we expressed both BADwt and $\mathrm{BAD}_{\mathrm{D} 119 \mathrm{G}}$ as GST fusion proteins and determined their interaction with $\mathrm{Bcl}-2$ proteins in lysates of Bcl-2-transfected HEK 293 cells. The purified GST, GST-BADwt and GST$B A D_{D 119 G}$ proteins used for the experiment are shown in Figure 2A. The fusion proteins were immobilized on glutathione beads and incubated with a total cell lysate of HEK 293 cells transfected with full-length, GFP-labeled Bcl-2 proteins. Binding of $\mathrm{Bcl}-2$ to the fusion proteins was detected following Western blotting with an anti-GFP antibody. As shown in Figure 2B only GST-BAD but not GST-BAD D119G $_{\text {or }}$ GST alone could specifically bind to $\mathrm{Bcl}-2$. Thus mutation of $\mathrm{BAD}$ at D119 can abolish its ability to bind to Bcl-2. To confirm this finding we also carried out the reciprocal experiment to determine if GST-Bcl-2 proteins could co-precipitate GFPBADwt or GFP-BAD ${ }_{\text {D119G }}$ proteins expressed in HEK 293 cells. The purified human full-length GST-Bcl-2 fusion protein used for this experiment is shown in Figure 2C. When GST$\mathrm{Bcl}-2$, immobilized on glutathione beads, was incubated with lysates of HEK 293 cells expressing GFP-BADwt or GFP$B A D_{\mathrm{D} 119 \mathrm{G}}$ only the BADwt and not the $B A D_{\mathrm{D} 119 \mathrm{G}}$, was 
$\mathbf{A}$

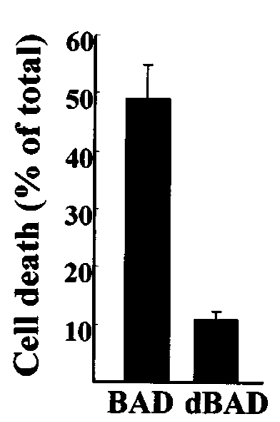

B

$\begin{array}{ll}\text { Bad } & \text { LRRMSDEFVDSFK } \\ \text { Bim } & \text { LRRIGDEFNAYYA } \\ \text { Bid } & \text { LAQVGDSMDRSIP } \\ \text { BNIP3 } & \text { LKKSADWVSDWSS } \\ \text { Bmf } & \text { LQCIADQFHRLHT } \\ \text { Noxa } & \text { LRRFGDKINERQK } \\ \text { Bax } & \text { LKRIGDEIDSNME } \\ \text { Bcl-X, } & \text { LREAGDEFELRYR } \\ \text { Bcl-2 } & \text { LRQAGDDFSRRYR }\end{array}$

$\mathbf{C}$

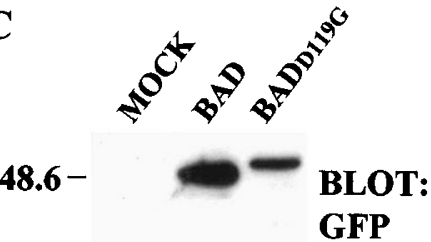

36.4-
D

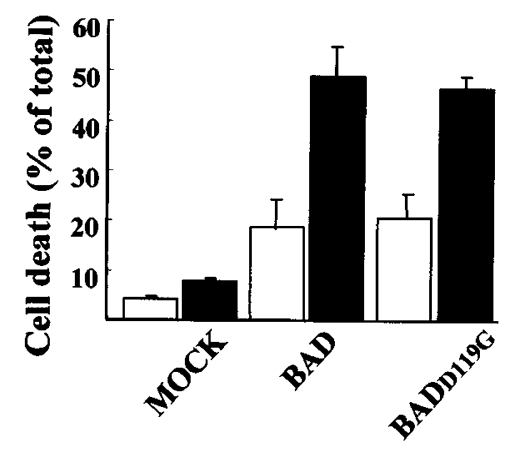

$\mathbf{E}$

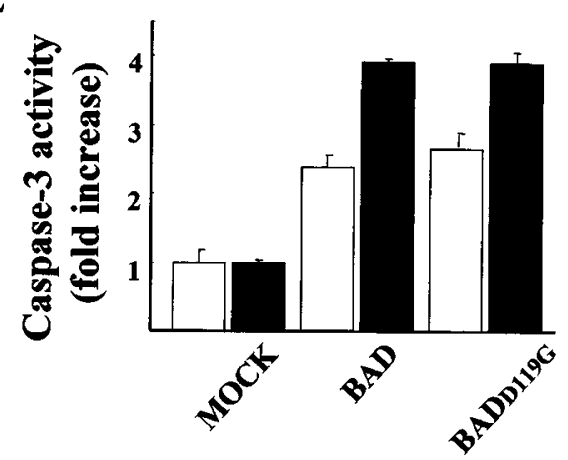

Figure 1 The $\mathrm{BAD}_{\mathrm{D} 119 \mathrm{G}}$ mutant has similar apoptotic activity to BADwt. (A) BAD overexpression augments cell death. COS-7 cells were transfected with the indicated expression vectors, and cultured in the absence of FCS for $24 \mathrm{~h}$ to induce the apoptotic process. Cell death was evaluated by trypan blue exclusion assay. The columns display the mean \pm standard deviation (S.D.) of data from three separate experiments. (B) Sequence homology of BH3 domains. Alignment of amino acid sequences of $\mathrm{BH} 3$ domains of $\mathrm{Bcl}-2$ family members including $\mathrm{BH}$-only proteins. Highly conserved sequences ( $\mathrm{L}$ and $\mathrm{D})$ are indicated in lines. (C) Overexpression of GFP-tagged BAD proteins. COS-7 cells were transiently transfected with control pEGFP vector alone (MOCK), GFP-human BADwt (BAD), or the GFP-BAD ${ }_{\mathrm{D} 119 \mathrm{G}}$ mutant $\left(\mathrm{BAD}_{\mathrm{D} 119 \mathrm{G}}\right)$. Transfectants were harvested at $24 \mathrm{~h}$ following transfection and subjected to immunoblot analysis with the anti-GFP antibody. The anti-Hsc70 antibody was used as a control to show the same amount of protein loaded in each lane. (D) BAD overexpression augments cell death. COS-7 cells were transfected with the indicated expression vectors and cultured in the absence of FCS for 12 (open bars) or $24 \mathrm{~h}$ (closed bars). Cell death was evaluated by trypan blue exclusion assay. The columns display the mean \pm S.D. of data from three separate experiments. (E) The BAD $\mathrm{D} 119 \mathrm{G}_{\mathrm{m}}$. activity to a similar extent as BADwt. COS-7 cells were transfected with the indicated vectors, and cultured in the absence of FCS for 9 (open bars) or $12 \mathrm{~h}$ (closed bars). Transfectants were washed with ice-cold PBS and caspase-3 activity was measured with a Caspase- 3 Colorimetric Protease Assay Kit. The numbers represent the fold increase in absorbance at $400 \mathrm{~nm}$ relative to the mock transfectants. Each column displays the mean \pm S.D. of data from three separate experiments

specifically co-precipitated by GST-Bcl-2 (Figure 2D). We thus conclude that mutation of BAD at D119 abrogates the binding of $B A D$ to $B c l-2$. Since $B A D_{D 119 G}$ can still induce apoptosis (Figure 1) this data indicates that the pro-apoptotic activity of BAD is not necessarily mediated via inhibition of the anti-apoptotic function of $\mathrm{Bcl}-2$.

The $B A D_{D 119 G}$ mutant is able to bind to $B c l-X_{L}$. and has similar anti-apoptotic activity in the presence of $\mathrm{Bcl}-2$ or $\mathrm{Bcl}-\mathrm{X}_{\mathrm{L}}$

Previous data, discussed above, suggests that the proapoptotic function of BAD may be mediated via its interaction with $\mathrm{Bcl}-\mathrm{X}_{\mathrm{L}}$ rather than $\mathrm{Bcl}-2$. $^{6}$ We thus determined whether mutation of $B A D$ at $D 119$ could also abrogate the binding of $\mathrm{BAD}$ to $\mathrm{Bcl}-\mathrm{X}_{\mathrm{L}}$. Incubation of GST-BAD fusion proteins with GFP-Bcl- $X_{L}$ clearly revealed that $B A D_{D 119 G}$ is able to bind to $\mathrm{BCl}-\mathrm{X}_{\mathrm{L}}$ (Figure $\left.3 \mathrm{~A}\right)$. The reciprocal experiment confirmed that $B A D_{\mathrm{D} 119 \mathrm{G}}$ can bind to $\mathrm{Bcl}-\mathrm{X}_{\mathrm{L}}$ (Figure $3 \mathrm{~B}$ ). This suggests that the observed pro-apoptotic activity of $\mathrm{BAD}_{\mathrm{D} 119 \mathrm{G}}$ (Figure 1) might be mediated by interaction of $B A D_{D 119 G}$ with $B c l-X_{L}$ and further suggests the hypothesis that $\mathrm{Bcl}-2$ may be irrelevant for the pro-apoptotic activity of BAD. As a further test of the importance of $\mathrm{Bcl}-2$ for BAD pro-apoptotic activity we determined whether the pro-apoptotic functions of BADwt and the $B A D_{D 119 G}$ mutant were affected differently following co-transfection with $\mathrm{Bcl}-2$ or $\mathrm{Bcl}-\mathrm{X}_{\mathrm{L}}$. Co-transfection of BADwt or $\mathrm{BAD}_{\mathrm{D} 119 \mathrm{G}}$ with $\mathrm{Bcl}-2$ or $\mathrm{Bcl}-\mathrm{X}_{\mathrm{L}}$ resulted in similar levels of expressed proteins in COS-7 cells (Figure 4A). Augmentation of caspase-3 activity following serum deprivation of transfected cells for $18 \mathrm{~h}$ was taken as a measure of apoptotic activity. Although a previous report demonstrated that BAD can reverse the anti-apoptotic activity of $\mathrm{Bcl}-\mathrm{X}_{\mathrm{L}}$ but not that of $\mathrm{Bcl}-2$ in hematopoietic transfectants, ${ }^{6}$ the augmented caspase-3 activity induced by BADwt or $\mathrm{BAD}_{\mathrm{D} 119 \mathrm{G}}$ (see Figure 1) was similarly inhibited following co-transfection of either of the $\mathrm{BAD}$ proteins with $\mathrm{Bcl}-2$ or $\mathrm{Bcl}-\mathrm{X}_{\mathrm{L}}$ (Figure $4 \mathrm{~B}$ ). Thus the proapoptotic function of BAD can be diminished by both $\mathrm{Bcl}-2$ and $\mathrm{Bcl}-\mathrm{X}_{\mathrm{L}}$. More importantly, since the anti-apoptotic activity of $\mathrm{Bcl}-2$ was similar in the presence of co-transfected BADwt or the $B A D_{\mathrm{D} 119 \mathrm{G}}$ mutant with which it cannot interact, this observation further suggests that interaction between $\mathrm{Bcl}-2$ and $B A D$ is marginal for the pro-apoptotic function of BAD at least in COS-7 cells. 
A

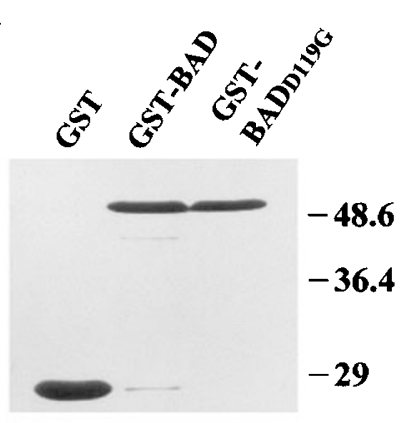

C

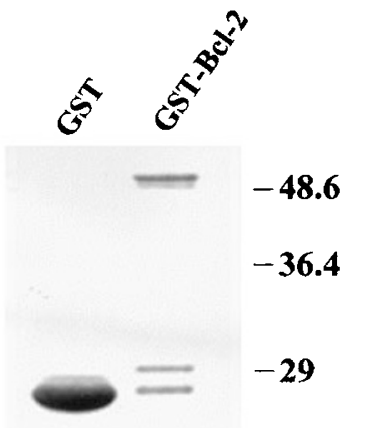

B

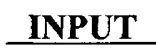

PULL-DOWN

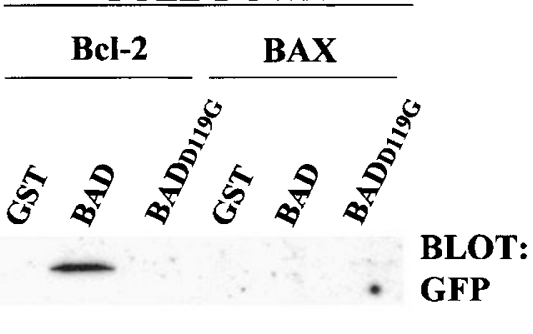

D

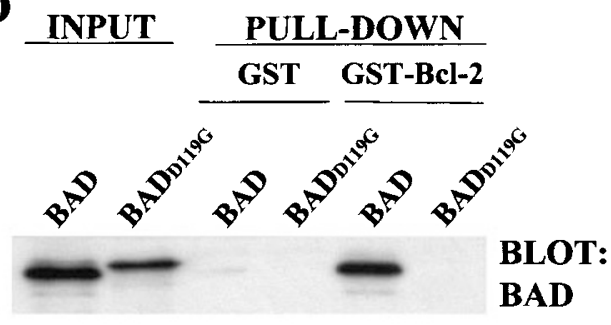

Figure 2 Interaction of human $B A D$ and $B A D_{D 119 G}$ mutant with $B C l-2$. (A) Expression of GST-BAD and GST-BAD $D_{D 119 G}$ fusion proteins. $10 \mu \mathrm{l}$ of glutathione-beadbound GST, GST-BAD or GST-BAD ${ }_{\mathrm{D} 119 \mathrm{G}}$ were loaded onto $12 \% \mathrm{SDS}-\mathrm{PAGE}$ and stained with Coomassie Blue G-250. Molecular size markers are shown in $\mathrm{kDa}$. (B) Specific binding of Bcl-2 proteins to the GST-BAD fusion protein. Cell lysates from HEK 293 cells transfected with GFP-tagged-Bcl-2 or -BAX (INPUT) were incubated with the indicated GST-fusion proteins. The proteins bound to the washed beads (PULL-DOWN) were resolved by $12 \%$ SDS -PAGE and identified by Western blotting using an anti-GFP antibody. (C) Expression of the GST-Bcl-2 protein. Glutathione beads bound by GST or GST-Bcl-2 were resolved on $12 \%$ SDS - PAGE and stained with Coomassie Blue G-250. Molecular size markers are shown in kDa. (D) Specific binding of BADwt but not BAD $119 \mathrm{Bg}$ to GST-Bcl-2.

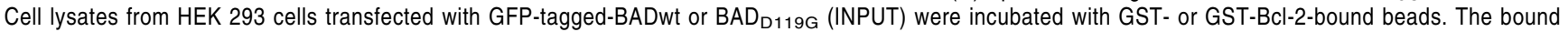
proteins were resolved by $12 \%$ SDS - PAGE and identified by Western blotting using an anti-BAD antibody. (BAD)

A

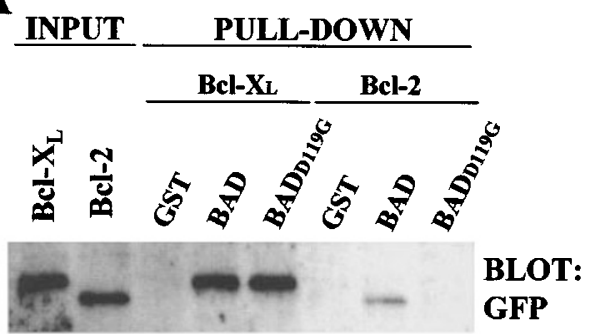

B

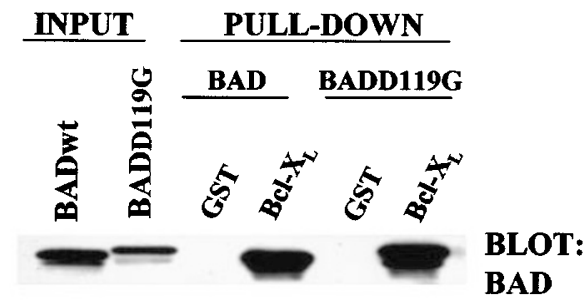

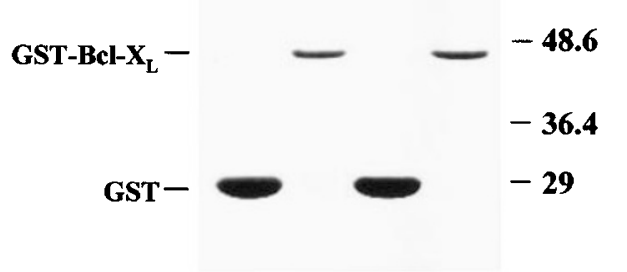

Figure 3 Effect of the D119G mutation on the physical and functional interaction of human BAD with $B c l-X_{L}$. (A) Interaction of $B c l-2$ and Bcl- $X_{L}$ with $G S T-B A D$ fusion proteins. Cell lysates from HEK 293 cells transfected with GFP-tagged Bcl-X $\mathrm{L}_{\mathrm{L}}$ or Bcl-2 (INPUT) were incubated with the indicated GST, GST-BAD or GST$B A D_{D 119 G}$-fusion proteins. Proteins bound to the washed beads were identified by Western blots using an anti-GFP antibody. (B) Specific binding of BADwt and

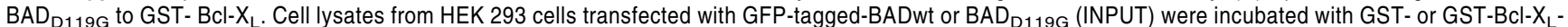
bound beads. The bound proteins were resolved by $12 \%$ SDS - PAGE and identified by Western blotting using an anti-BAD antibody (BAD). The loaded SDSPAGE gel was stained with Coomassie Blue G-250 and shows specific binding of both $B A D$ and $B A D_{D 119 G}$ to $B c l-X_{L}$ (lower panel). Molecular size markers are shown in $\mathrm{kDa}$ 
$\mathbf{A}$

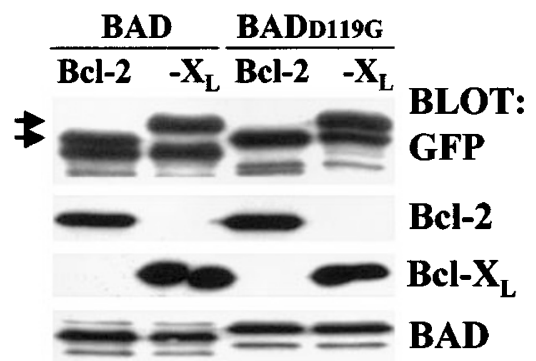

B

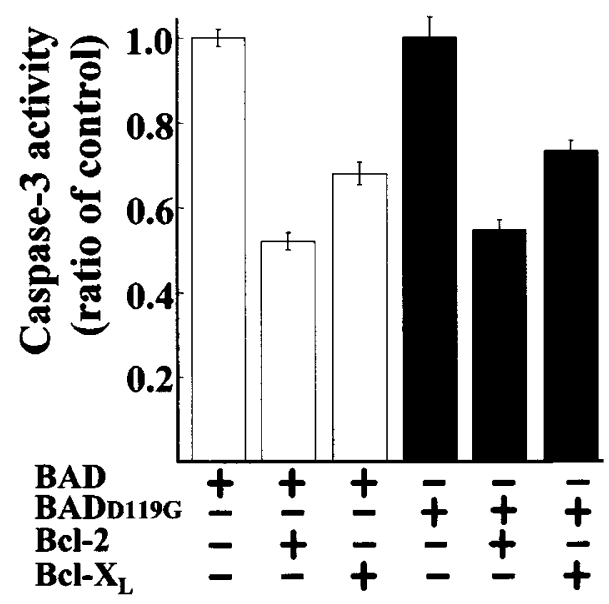

Figure 4 Effect of $B A D$ and $B A D_{\mathrm{D} 119 \mathrm{G}}$ overexpression on $\mathrm{Bcl}-2$ or $\mathrm{Bcl}-\mathrm{X}_{\mathrm{L}}$ functions. $(\mathrm{A})$ Expression of co-transfected $\mathrm{GFP}$-tagged-BADwt or $\mathrm{BAD}$-119G with $\mathrm{Bcl}$-2 or - $\mathrm{Bcl}-\mathrm{X}_{\mathrm{L}}$ proteins. COS-7 cells were transiently co-transfected with the indicated expression vectors. Transfectants were harvested at $24 \mathrm{~h}$ following transfection and subjected to immunoblot analysis using the indicated antibodies. Arrows indicate the bands corresponding to GFP-Bcl- $\mathrm{X}_{\mathrm{L}}$ (upper) and GFP-Bcl-2 (lower). (B) $B A D$ and $B A D_{D 119 G}$ display a similar inhibitory effect on death repressor activity of $\mathrm{Bcl}-2$ and $\mathrm{Bcl}-\mathrm{X}_{\mathrm{L}}$. COS-7 cells were co-transfected with the indicated vectors, and cultured in the absence of FCS for $18 \mathrm{~h}$. Transfectants were washed with ice-cold PBS and caspase-3 activity was measured with the Caspase- 3 Colorimetric Protease Assay Kit. The numbers represent the fold decrease in absorbance at $400 \mathrm{~nm}$ relative to the BAD/Mock or BAD $1119 \mathrm{G} / \mathrm{Mock}$ transfectants. Each column displays the mean \pm S.D. of data from three separate experiments, which consistently produced quite similar results

\section{The $B A D_{\mathrm{D} 119 \mathrm{G}}$ mutant is targeted to mitochondria}

It is well established that BAD is activated and targeted to the mitochondria during the induction of the apoptotic process following exposure of cells to a variety of apoptotic stimuli or following deprivation of survival signals. ${ }^{6,7,16-18}$ We thus used GFP-tagged BADwt and $B A D_{D 119 G}$ constructs to investigate if mutation of BAD at D119 could alter its subcellular localization in COS-7 cells grown under normal or apoptosis-inducing conditions. Transfected COS-7 cells were therefore cultured in the presence (normal conditions) or absence (apoptosis-inducing conditions) of FCS. In FCSdeprived transfectants, confocal microscopical analysis revealed that both GFP-tagged BADwt and the $B A D_{\mathrm{D} 119 \mathrm{G}}$ mutant are visible in the cytoplasm at $12 \mathrm{~h}$ following genetransfection, especially at the perinuclear region. At $24 \mathrm{~h}$ following transfection, extensive overlap of the GFP-BAD signals with the mitochondrial MitoTracker marker dye was observed (Figure 5). When transfectants were cultured in the medium in the presence of FCS, the overlap of the BAD signals with mitochondria was substantially reduced although still observable (data not shown). These results suggested both that overexpression of BAD per se can result in localization of activate $B A D$ to the mitochondria and that the mutant $B A D_{D 119 G}$ maintains its ability to be targeted to the mitochondria both in response to apoptotic stimuli and even independently of them. (Figure 5). In contrast BAD deletion mutants, in which the $\mathrm{BH} 3$ domain has been completely removed, did not show any distinct overlap with MitoTracker regardless of the culture conditions. Thus, although the $\mathrm{BH} 3$ domain of $B A D$ is required for targeting to mitochondria, mutation of $D 119$ to $G$ within this domain does not alter BAD mitochondrial localization. Since this mutation abrogates interaction of $\mathrm{BAD}$ with $\mathrm{Bcl}-2$ this data also suggests that mitochondrial targeting of $\mathrm{BAD}$ does not require interaction with Bcl-2 and provides further support for the hypothesis that $\mathrm{Bcl}-2$ interaction is not important for BAD pro-apoptotic function.

\section{Discussion}

In this paper we demonstrate that the pro-apoptotic activity of $\mathrm{BAD}$ is not mediated by interaction with $\mathrm{Bcl}-2$ and subsequent inhibition of Bcl-2 anti-apoptotic activity. Studies carried out to date provided indirect evidence that BAD pro-apoptotic activity selectively neutralizes $\mathrm{Bcl}-\mathrm{X}_{\mathrm{L}}$, but not $\mathrm{Bcl}-2$. $^{6,8}$ In this study we demonstrated that BAD can neutralize both $\mathrm{Bcl}-2$ and $\mathrm{Bcl}-\mathrm{X}_{\mathrm{L}}$ at a similar level in COS-7 cells. In addition, a $B A D_{\mathrm{D} 119 \mathrm{G}}$ mutant that is unable to bind $\mathrm{Bcl}-2$, still retains its pro-apoptotic activity and can neutralize both $\mathrm{Bcl}-2$ and $\mathrm{Bcl}-$ $X_{L}$. These data strongly suggest that previous observations showing selective inhibitory effect of $B A D$ on $B c l-X_{L}$ is not general. Indeed, a recent report shows that BAD can induce apoptosis in cells overexpressing $\mathrm{Bcl}-2$ or $\mathrm{Bcl}-\mathrm{X}_{\mathrm{L}}$ in $\mathrm{COS}-7$ and leukemic cells. ${ }^{19}$ Thus, previous data could not exclude the possibility that BAD cannot neutralize $\mathrm{Bcl}-2$ because of its strong anti-apoptotic activity in some cell types. In this regard, we have conclusively shown that neutralization of $\mathrm{Bcl}-2$ functions is totally dispensable for the pro-apoptotic activity of BAD.

Recently, a novel phosphorylation site, S170 has been identified as a regulator of BAD pro-apoptotic activity. Since mutation of this region (Ser170 to Ala) results in an enhanced ability of BAD to induce apoptosis, phosphorylation of BAD at $S 170$ contributes to inactivation of its proapoptotic activity. ${ }^{20}$ Importantly, the inactive mutant (Ser170 to Asp) can still associate with $\mathrm{Bcl}-\mathrm{X}_{\mathrm{L}}$, although they do not induce apoptosis. Thus, the association of BAD with $B c l-X_{L}$ is not sufficient to introduce apoptosis. This implies that though retained pro-apoptotic functions of our mutant 

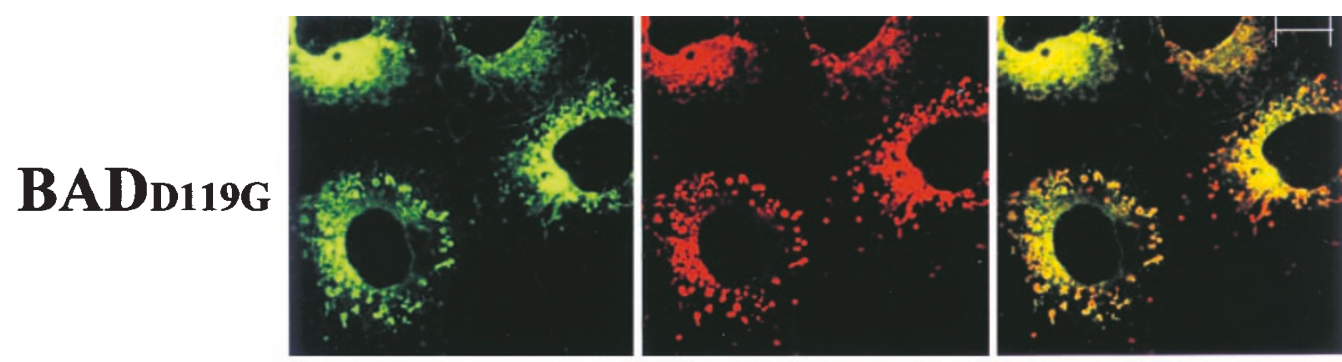

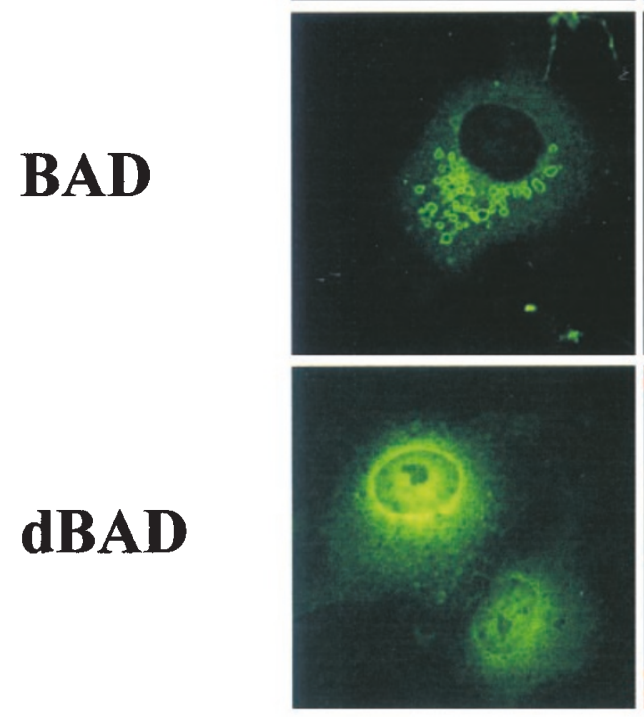

GFP
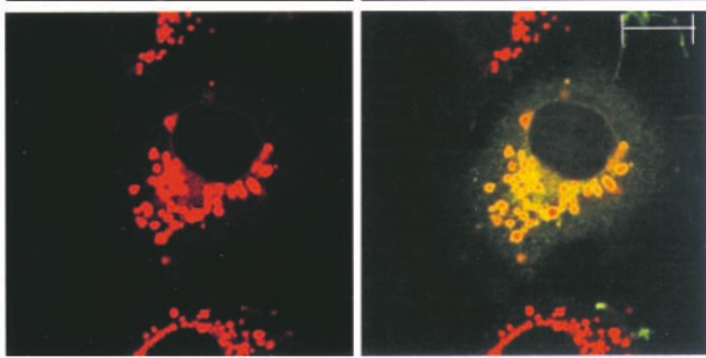

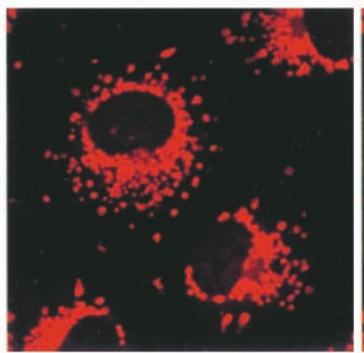

MitoTracker

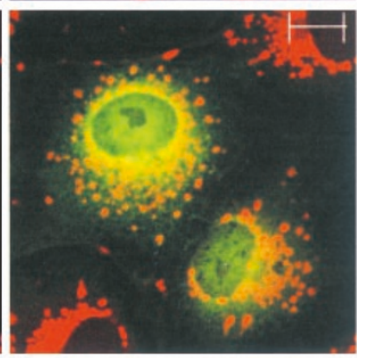

Merge

Figure 5 Mitochondrial localization of BADwt, BAD ${ }_{\mathrm{D} 119 \mathrm{G}}$ and $\mathrm{dBAD}$. COS-7 cells were transfected with either pEGFP-BADwt (BAD), pEGFP-BAD ${ }_{\mathrm{D} 119 \mathrm{G}}$ or pEGFP-dBAD (aa1-72) (green as indicated) and deprived of FCS for $24 \mathrm{~h}$ to induce apoptosis. Cellular mitochondria were then stained with MitoTracker (red) for $30 \mathrm{~min}$. The cells were fixed with methanol at $-20^{\circ} \mathrm{C}$. Images were obtained by confocal laser microscopy. An overlay of the BAD and mitochondrial images is indicated at right (Merge) in which co-localization is indicated by a yellow color. Bars, $10 \mu \mathrm{m}$

$\mathrm{BAD}_{\mathrm{D} 119 \mathrm{G}}$ appears to depend upon its ability to interact with $\mathrm{Bcl}-\mathrm{X}_{\mathrm{L}}$, other or additional mechanism(s) may rather be involved in its pro-apoptotic activity.

As shown in this and previous papers, ${ }^{8}$ deletion of the entire $\mathrm{BH} 3$ domain of $\mathrm{BAD}$ abrogates both mitochondrial targeting and the pro-apoptotic functions of BAD. Thus, $\mathrm{BH} 3$ is a crucial region for pro-apoptotic functions of BAD. The $\mathrm{BH} 3$ domain of $\mathrm{BAD}$ contains two conserved residues, an $L$ at position 114 and $a$ D a a119. A previous report indicated that mutation of the $L$ residue strongly reduces the ability of BAD to interact with $\mathrm{Bcl}-\mathrm{X}_{\mathrm{L}}$ or $\mathrm{Bcl}-2$ and destroys BAD pro-apoptotic functions. ${ }^{8}$ In this study, we found that a single amino acid substitution of BAD at D119 within the $\mathrm{BH} 3$ domain selectively destroyed its ability to interact with $\mathrm{Bcl}-2$, but not with $\mathrm{Bcl}-\mathrm{X}_{\mathrm{L}}$. In this regard, our study sheds light on the importance of the three-dimensional (3D) conformation of the $\mathrm{BH} 3$ domain in $\mathrm{BAD}$ function. To date, there have been several studies of the solution structures of Bcl-2 family members. Studies of Bid and $\mathrm{Bcl}-\mathrm{X}_{\mathrm{L}}$ reveal that their $\mathrm{BH} 3$ domains contain an $\alpha$ helical structure in which highly conserved hydrophobic residues (including the conserved $L$ residue) are surface exposed and available for binding to a hydrophobic cleft in another molecule. ${ }^{21-23}$ This hydrophobic cleft is considered to be crucial for the formation of heterodimers with other
Bcl-2 family members. In contrast, the side chain of the highly conserved charged residue D95 of Bid extends towards the interior of Bid yet is partially surface exposed and is thus in a position to form a salt bridge with another $\mathrm{Bcl}-2$ family member. ${ }^{22}$ The predicted structure of BAD indicates that the charged D156 residue in murine BAD (D119 in human BAD) is similarly positioned. ${ }^{8}$ Thus, it seems likely that the D119 residue, which was mutated in this study, may contribute to the formation of a salt bridge which is crucial for heterodimerization with $\mathrm{Bcl}-2$, but not with $\mathrm{Bcl}-\mathrm{X}_{\mathrm{L}}$

Our data also indicate that the interaction of BAD with $\mathrm{Bcl}-2$ is marginal for its recruitment to the mitochondria. Previous reports suggest that $\mathrm{BAX}$ can contribute to the recruitment of Bid to the mitochondria. ${ }^{24,25}$ However, there has been little information regarding the mechanism of mitochondrial targeting of BAD. Since neither we, nor others, ${ }^{26}$ can detect a distinct interaction between BAX and $\mathrm{BAD}$ in co-precipitation assays (Figure 2), it is unlikely that BAX can directly translocate BAD to the mitochondria. It is rather conceivable that the interaction with $B c l-X_{L}$ is required for the translocation, since our mutant $B A D_{D 119 G}$ can interact only with $\mathrm{Bcl}-\mathrm{X}_{\mathrm{L}}$ and has an ability to translocate to the mitochondria. It must be noted however that tBid expression induces a conformational change in 
the amino-terminus of Bax, which allows BAK/BAX oligomerization and subsequent pore formation. ${ }^{27,28}$ Since the interaction between tBid and BAX is transient, it is difficult to detect their interaction and tBid is thus believed to act by a 'hit-and-run' mechanism to activate BAX. Since $B A D$ is also cleaved and activated during the apoptotic process, ${ }^{29}$ and its pro-apoptotic functions absolutely require BAX/BAK expression, ${ }^{13}$ we cannot exclude the possibility that BAX can transiently interact with the cleaved BAD and transport it to the mitochondria. Whatever the transport mechanism is, mutant $\mathrm{BAD}_{\mathrm{D} 119 \mathrm{G}}$ can be translocated to the mitochondria as BADwt, and thus $D$ residue within the $\mathrm{BH} 3$ domain is not necessary for the recruitment. Since mitochondrial targeting of $B A D$ is obviously crucial for its apoptotic process, clarification of the precise molecular mechanism is an important avenue of future research.

\section{Materials and methods}

\section{Cell culture and transfection}

Green monkey kidney epithelial COS-7 and human embryonal HEK 293 cells were provided from the Japanese Cancer Research Resources Bank (Tokyo, Japan) and grown in Dulbecco-modified Eagles medium (D-MEM) supplemented with $10 \%$ fetal calf serum (FCS) at $37^{\circ} \mathrm{C}$ in $5 \% \mathrm{CO}_{2}$. The cDNA $\left(3 \mu \mathrm{g} / \mathrm{cm}^{2}\right)$ constructs described below were transfected into these cells as indicated in the text using LipofectAMINE 2000 Reagent (GIBCO Life and Technologies, MD, USA) or Effectene (Qiagen, CA, USA).

\section{Plasmids}

Mutant BAD, in which Asp119 was replaced with Gly (BADD119G), was generated according to a PCR mutagenesis method. ${ }^{30} \mathrm{PCR}$ was performed with the following oligonucleotide primers: $5^{\prime}$-CCGGAGGATGAGTGGCGAGT TTGTGGAC-3' and 5'-GTCCACAAACTCGCCACTCATCCTCCGG-3' (corresponding to nucleotides 342-369 in the human BAD CDNA). Full-length human BAD cDNA, (BADwt, kindly provided by Dr. JC Reed of the Burnham Institute), mutant BAD, fulllength human $\mathrm{Bcl}-2^{31}$ and $\mathrm{Bcl}-\mathrm{X}_{\mathrm{L}}{ }^{32}$ (kindly provided by $\mathrm{Dr}$. $\mathrm{Y}$ Tsujimoto, Osaka University, Japan) were subcloned into GFP expression vectors $\mathrm{pEGFPs}$ (Clontec, CA, USA). $\mathrm{BAD}_{\mathrm{D} 119 \mathrm{G}}, \mathrm{BADwt}$, and $\mathrm{Bcl}-2$ cDNAs were also subcloned into the prokaryote pGEX 4T expression vectors (Pharmacia) for the generation of GST-fusion proteins. BAD C-terminal $\mathrm{BH} 3$ domain deletion mutants were generated by PCR using two different sets of oligonucleotide primers: 5'-GCGGATCCGCGGCCCCGAAAGGGGCTGGGC-3' and 5'GCGGATCCGCCACCATGTT CCAGATCCCAGAG-3' (corresponding to amino acids 1-72 in human $B A D$ ), and were subcloned into the mammalian expression plasmids pcDNA3 and pEGFP.

\section{Reagents and antibodies}

Antibody against $B A D$ and $B c l-X_{L}$ were purchased from Cell Signaling Technology (Beverly, MA, USA) and Transduction Labs (San Diego, CA, USA), respectively. Antibodies against Hsc70, BAD, Bcl-2, and GFP were from Santa Cruz Biotechnology Inc. (Santa Cruz, CA, USA).

\section{Apoptosis quantification}

To evaluate cell viability, cells were mixed with the same volume of $0.4 \%$ trypan blue solution, and immediately examined under the light microscope for dye exclusion. The caspase-3 colorimetric protease assay was performed following the manufacturer s protocol (CPP32/ Caspase-3 Colorimetric Protease Assay Kit, MBL). Briefly $1 \times 10^{6}-$ $10^{7}$ cells were lysed in $250 \mu \mathrm{l}$ of Cell Lysis Buffer. Total cell lysates were collected and their protein concentration was evaluated using a Protein Assay (BioRad, NY, USA). These lysates (100 $\mu \mathrm{g})$ were mixed with the same volume of $2 \times$ Reaction Buffer, and incubated with the $4 \mathrm{mM}$ DEVD-pNA caspase- 3 substrate (200 $\mu \mathrm{M}$ final concentration) at $37^{\circ} \mathrm{C}$ for $2 \mathrm{~h}$. The samples were then analysed at $400 \mathrm{~nm}$ in a spectrophotometer.

\section{Western blotting}

As described previously, ${ }^{33}$ following washing with ice-cold PBS, cells were lysed with $50 \mu \mathrm{l}$ of lysis buffer containing $100 \mathrm{mM} \mathrm{NaCl}, 2 \mathrm{mM}$ EDTA, $1 \mathrm{mM}$ PMSF, $1 \% \mathrm{NP}-40$ and $50 \mathrm{mM}$ Tris- $\mathrm{HCl}(\mathrm{pH} 7.2)$. Total cell lysates were collected, separated in 15\% SDS-PAGE gels ( $80 \mu \mathrm{g} /$ lane) and then electrophoretically transferred to PVDF membranes (Millipore, MA, USA) at $18 \mathrm{~V}$ for $70 \mathrm{~min}$. Membranes were soaked into Block Ace (Dainippon Pharmacia Co., Japan) overnight at $4^{\circ} \mathrm{C}$ and washed with washing buffer containing $140 \mathrm{mM}$ $\mathrm{NaCl}, 25 \mathrm{mM}$ Tris- $\mathrm{HCl}(\mathrm{pH} \mathrm{7.8)}$ and 0.05\% Tween 20. The membranes were incubated with primary antibodies overnight at $4{ }^{\circ} \mathrm{C}$ and thereafter incubated with the corresponding peroxidase-linked secondary antibodies (Amersham Pharmacia Biotech, IL, USA) for $1 \mathrm{~h}$ at room temperature. Blots were visualized by an ECL system (Amersham Pharmacia Biotech).

\section{GST fusion protein expression and co-precipitation assays}

pGEX plasmids encoding full-length $B A D w t, B_{D 119 G}$, and $\mathrm{Bcl}-2$ as GST fusion proteins were generated as described above. Expression of the fusion proteins was induced in BL21-competent bacteria with isopropyl- $\beta$-D-thiogalactoside and the fusion proteins were purified. For control experiments GST alone was generated from the pGEX-4T vector. Briefly, the bacteria were lysed with sodium deoxycholate, and the supernatant was collected and incubated with a $50 \%$ slurry of glutathione-sepharose 4B (Amersham Pharmacia Biotech). The beads were washed and resuspended in $10 \mathrm{mM}$ Tris, pH 7.4, $150 \mathrm{mM} \mathrm{NaCl}$, $5 \%$ glycerol, $1 \%$ phenylmethylsulfonyl fluoride and $1 \mu \mathrm{g} / \mathrm{ml}$ leupeptin. The concentration of GST-fusion-protein bound to the beads was estimated visually from Coomassie Blue-stained SDS-PAGE with albumin standards. For co-precipitation assays whole cell lysates (1 mg) of HEK 293 transfected cells described above were incubated with $20 \mu \mathrm{l}$ of GST-fusion-protein-bound beads for $1-2 \mathrm{~h}$ at $4^{\circ} \mathrm{C}$. The beads were washed at least five times with ice-cold lysis buffer followed by separation via SDS-PAGE. Proteins were then subjected to Western blot analysis.

\section{Confocal laser microscopy}

COS-7 cells were cultured on BSA-coated glass slides and transfected with the indicated expression vectors. Twenty-four hours following transfection, the cells were washed with cold PBS and thereafter fixed with cold methanol for $10 \mathrm{~min}$. To visualize mitochondria, cells were incubated in D-MEM containing $500 \mathrm{nM}$ MitoTracker RED CMXRos (Molecular Probes, OR, USA). Cells were washed three times with PBS and the coverslips were mounted on glass-slides using VECTASHILD (Vector Laboratories, Burlingame, CA, USA). Images were taken with an inverted confocal laser scanning microscopy (LSM 510; Zeiss, Jena, Germany) with a $100 \times$ oil objective lens, and processed by Adobe Photoshop version 5.0. 


\section{Acknowledgements}

We thank Drs. JC Reed (Burnham Institute) and Y Tsujimoto for providing cDNAs, and Ms Miyuki Itoh for helping with construction of plasmids and generation of mutant BAD. Supported by Grants-in-Aid for Cancer Research and for Scientific Research from the Ministry of Education, Science, Sports and Culture of Japan (M Aadachi, K Imai).

\section{References}

1. Adams JM and Cory S (1998) The Bcl-2 protein family: arbiters of cell survival. Science 281: $1322-1326$

2. Gross A, McDonnellJMand Korsmeyer SJ (1999)BCL-2 family members and the mitochondria in apoptosis. Genes Dev. 13: 1899-1911

3. Kelekar A and Thompson CB (1998) Bcl-2-family proteins: the role of the $\mathrm{BH} 3$ domain in apoptosis. Trends Cell Biol. 8: 267-271

4. Puthalakath $\mathrm{H}$, Villunger $A$, O'Reilly LA, Beaumont JG, Coultas L, Cheney RE, Huang DCS and Strasser A (2001) Bmf: A proapoptotic BH3-only protein regulated by interaction with the myosin $\mathrm{V}$ actin motor complex, activated by anoikis. Science 293: $1829-1832$

5. Oda E, Ohki R, Murasawa H, Nemoto J, Shibue T, Yamashita T, Tokino T, Taniguchi T and Tanaka N (2000) Noxa, a BH3-only member of the Bcl-2 family and candidate mediator of p53-induced apoptosis. Science 288: 1053-1058

6. Yang E, Zha J, Jockel J, Boise LH, Thompson CB and Korsmeyer SJ (1995) Bad a heterodimeric partner for $\mathrm{Bcl}-\mathrm{XL}$ and $\mathrm{Bcl}-2$, displaces Bax and promotes cell death. Cell 80: 285-291

7. Zha J, Harada H, Yang E, Jockel J and Korsmeyer SJ (1996) Serine phosphorylation of death agonist $B A D$ in response to survival factor results in binding to 14-3-3 not BCL-XL. Cell 87: 619-628

8. Zha J, Harada H, Osipov K, Jockel J, Waksman G and Korsmeyer SJ (1997) BH3 domain of BAD is required for heterodimerization J. Biol. Chem. 272: 24101 24104

9. O'Connor L, Strasser A, O'Reilly LA, Hausmann G, Adam JM, Cory S and Huang DC (1998) Bim: a novel member of the Bcl-2 family that promotes apoptosis. EMBO J. 17: 384-395

10. LiH, Zhu H, Xu CJ and Yuan J (1998) Cleavage of BID by caspase 8 mediates the mitochondrial damage in the Fas pathway of apoptosis. Cell 94: 491-501

11. LuoX, Budihardjo I,Zou H, Slaughter C and Wang X (1998) Bid, a Bcl2 interacting protein, mediates cytochrome $c$ release from mitochondria in response to activation of cell surface death receptors. Cell 94: 481-490

12. WeiMC, Lindsten T, Mootha VK, Weiler S, Gross A, Ashiya M, Thompson CB and Korsmeyer SJ (2000) tBID, a membrane-targeted death ligand, oligomerizes BAK to release cytochrome c. Genes Dev. 14: 2060-2071

13. Zong W-X, Lindsten T, Ross AJ, MacGregor GR and Thompson CB (2001) BH3only proteins that bind pro-survival $\mathrm{Bcl}-2$ family members fail to induce apoptosis in the absence of Bax and Bak. Genes Dev. 15: 1481-1486

14. Hirai I and Wang H-G (2001) Survival-factor-induced phosphorylation of Bad results in its dissociation from Bcl-x (L) but not Bcl-2. Biochem. J. 359: 345-352

15. Kitada S, Krajewska M, Zhang X, Scudiero D, Zapata JM, Wang HG, Shabaik A Tudor G, Krajewski S, Myers TG, Johnson GS, Sausville EA and Reed JC (1998) Expression and location of pro-apoptotic $\mathrm{Bcl}-2$ family protein $\mathrm{BAD}$ in normal human tissues and tumor cell lines. Am. J. Pathol. 152: 51-61
16. Nechushtan A, Smith CL, Lamensdorf I, Yoon S-H and Youle RJ (2001) Bax and Bak coalesce into novel mitochondria-associated clusters during apoptosis. J. Cell Biol. 153: 1265-1276

17. Kelekar A, Chang BS, Harlan JE, Fesik SW and Thompson CB (1997) Bad is a $\mathrm{BH} 3$ domain-containing protein that forms an inactivating dimer with $\mathrm{Bcl}-\mathrm{XL}$. Mol. Cell. Biol. 17: 7040-7046

18. Wang HG, Pathan N, Ethell IM, Krajewski S, Yamaguchi Y, Shibasaki F, McKeon F, Bobo T, Franke TF and Reed JC (1999) Ca2t-induced apoptosis through calcineurin dephosphorylation of BAD. Science 284: $339-343$

19. Schimmer AD, Hedley DW, Pham NA, Chow S and Minden MD. (2001) BAD induces apoptosis in cells over-expressing $\mathrm{Bcl}-2$ or $\mathrm{Bcl}-\mathrm{xL}$ without loss of mitochondrial membrane potential. Leuk Lymphoma 42: 429-443

20. Dramsi S, Scheid MP, Maiti A, Hojabrpour P, Chen X, Schubert K, Goodlett DR Aebersold R and Duronio V. (2002) Identification of a Novel Phosphorylation Site, Ser-170, as a Regulator of Bad Pro-apoptotic Activity. J. Biol. Chem. 277: $6399-6405$

21. Chou JJ, Li H, Salvesen GS, Yuan J and Wagner G (1999) Solution structure of BID, an intracellular amplifier of apoptotic signaling. Cell 96: 615-624

22. McDonnell JM, Fushman D, Milliman CL, Korsmeyer SJ and Cowburn D (1999) Solution structure of the proapoptotic molecule BID: a structural basis for apoptotic agonists and antagonists. Cell 96: 625-634

23. Petros AM, Medek A, Nettesheim DG, Kim DH, Yoon HS, Swift K, Matayochi ED, Oltersdorf T and Fesik SW (2001) Solution structure of the antiapoptotic protein bcl-2. Proc. Natl. Acad. Sci. USA 98: 3012-3017

24. Wang K, Gross A, Waksman G and Korsmeyer SJ (1998) Mutagenesis of the $\mathrm{BH} 3$ domain of $\mathrm{BAX}$ identifies residues critical for dimerization and killing. Mol. Cell Biol. 18: 6083-6089

25. Wang K, Yin X-M, Chao DT, Milliman CL and Korsmeyer SJ (1996) BID: a novel BH3 domain-only death agonist. Genes Dev. 10: 2859-2869

26. Ottilie S, Diaz JL, Horne W, Chang J, Wang Y, Wilson G, Chang S, Weeks S, Fritz LC and Oltersdorf T (1997) Structural and functional complementation of an inactive Bcl-2 mutant by Bax truncation. J. Biol. Chem. 272: 30866-30872

27. Wei MC, Lindsten T, Mootha VK, Weiler S, Gross A, Ashiya M, Thompson CB and Korsmeyer SJ (2000) tBID, a membrane-targeted death ligand, oligomerizes BAK to release cytochrome c. Genes Dev. 14: 2060-2071

28. Wei MC, Zong W-X, Cheng EH-Y, Lindsten T, Panoutsakopoulou V, Ross AJ, Roth KA, MacGregor GR, Thompson CB and Korsmeyer SJ (2001) Proapoptotic $B A X$ and BAK: a requisite gateway to mitochondrial dysfunction and death. Science 292: 727-730

29. Condorelli F, Salomoni P, Cotteret S, Cesi V, Srinivasula SM, Alnemri ES and CalabrettaB (2001) Caspase cleavage enhances the apoptosis-inducing effects of BAD. Mol. Cell Biol. 21: 3025-3036

30. Vallette F, Mege E, Reiss A and Milton A (1989) Construction of mutant and chimeric genes using the polymerase chain reaction. Nucleic Acid Res. 17:723733

31. Takaoka A, Adachi M, Okuda H, Sato S, Yawata A, Hinoda Y, Takayama S, Reed JC and Imai K (1997) Anti-cell death activity promotes pulmonary metastasis of melanoma cells. Oncogene 14: 2971-2977

32. Shimizu S, Eguchi Y, Kosaka H, Kamiike W, Matsuda H and Tsujimoto Y (1995) Prevention of hypoxia-induced cell death by Bcl-2 and Bcl-xL. Nature 374: 811 813

33. Yawata A, Adachi M, Okuda H, Naishiro Y, Takamura T, Hareyama M, Takayama S, Reed JC and Imai K (1998) Prolonged cell survival enhances peritoneal dissemination of gastric cancer cells. Oncogene 16: 2681-2686 